Bangladesh J. Bot. 49(2): 375-385, 2020 (June)

\title{
THE CHANGE TREND IN PHYSIOLOGICAL TRAITS OF 110 CITRUS ACCESSIONS IN RESPONSE TO COLD STRESS
}

\author{
Abouzar Abouzari ${ }^{1}$, Mahmood Solouki*, Behrouz Golein ${ }^{2}$, \\ Barat Ali Fakheri and Atefeh Sabouri ${ }^{3}$ \\ Department of Plant Breeding and Biotechnology, Faculty of Agriculture, \\ University of Zabol, Zabol, Iran
}

Keywords: Abiotic stress, Citrus, Cold tolerance, Selection value, Unknown biotypes

\begin{abstract}
In order to investigate the change process of some physiological indices in response to four temperature levels $\left(3,0,-3\right.$ and $\left.-6^{\circ} \mathrm{C}\right), 110$ Citrus accessions consisting of 76 unknown natural biotypes and 34 known genotypes were studied using the split-plot design with three replications. Two genotypes Poncirus and Mexican lime (as cold tolerant and cold susceptible, respectively) were used as control genotypes. Electrolyte leakage, leaf water soaking, and lipid peroxidation had increasing trends with the decrease of temperature. On the other hand, for tolerance criteria (antioxidant capacity, proline content, total carbohydrates, and enzymatic activities) sigmoidal trends were recorded. For electrolyte leakage and leaf water soaking, Poncirus, Satsuma mandarin, and the unknown biotype G8 had the smallest range of mean variation at four stress temperatures. Also, for lipid peroxidation, Siavaraz 1, Satsuma mandarin, and sour orange had the lowest range of change. Proline content evaluation showed that Satsuma mandarin and two natural biotypesMoallemkoh and Siavaraz 2-experienced the highest changes in proline accumulation.
\end{abstract}

\section{Introduction}

Since most citrus cultivation areas may have a lower temperature in winter than optimum production conditions, low-temperature stress is frequently one of the environmental limiting factors in the cultivation and production of this evergreen subtropical plant (Tajvar et al. 2011). In a study conducted on the effects of cold stress (CS) on Satsuma mandarin, it was reported that with a decrease in temperature, the rate of electrolyte leakage increased (Nesbitt et al. 2002). Based on the researches done, CS was found to cause increased enzymatic activity in mandarin cultivars (Sala and Lafuente 1999). It has also been reported that various sour orange cultivars have more antioxidant enzymatic activities (Lindhout 2007).

Ramsar Citrus Germplasm Collection is the most important source of citrus germplasm in Iran. Many accessions in this collection are natural biotypes that have shown different responses to CS in recent years. Therefore, the present study was designed and conducted in order to understand the physiological responses of different genotypes to different levels of CS, as well as the change process of the values of traits.

\section{Materials and Methods}

The present research was carried out performed in a split-plot design with three replications. Low- temperature stress, with an assessment of eight cold tolerance (CT) - related traits, was evaluated at four temperature levels viz. $3,0,-3$ and $-6^{\circ} \mathrm{C}$ as main factors and 110 genotypes (Table 1) as sub-factor levels. For this purpose, one-year-old branches containing leaf at a length of $30 \mathrm{~cm}$ were collected from 110 different accessions from Iran Citrus and Subtropical Fruit

\footnotetext{
*Author for correspondence: <mahmood1solouki@gmail.com>. ${ }^{1}$ Agricultural Research and Education Center, AREEO, Mazandaran, Iran. ${ }^{2}$ Citrus and Subtropical Fruits Research center, Horticultural Sciences Research Institute, Agricultural Research, Education and Extension Organization, Ramsar, Iran. ${ }^{3}$ Department of Agronomy and Plant Breeding, Faculty of Agricultural Sciences, University of Guilan, Rasht, Iran.
} 


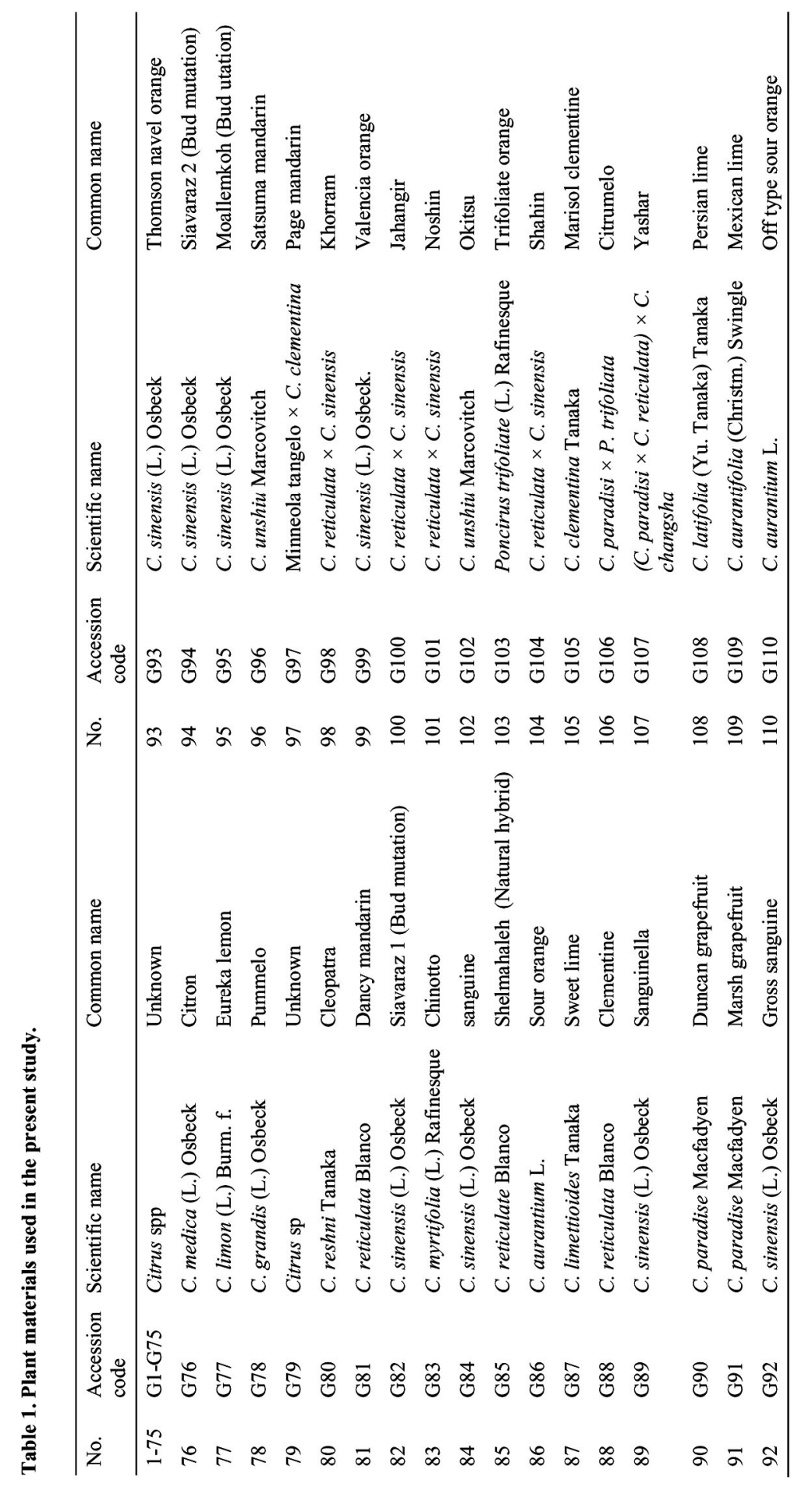


Research Center (lat. $36^{\circ} 54^{\prime} 26^{\prime \prime} \mathrm{N}$, long. $50^{\circ} 39^{\prime} 24^{\prime \prime} \mathrm{E}$, alt. $-3 \mathrm{~m}$ ). The selected branches were placed within the thermo-gradient freezer (Pars-Model) under low-temperature treatment. The samples were incubated for eight hours at each treatment temperature before the trait measurements with the temperature decrement setting as $1^{\circ} \mathrm{C} / \mathrm{hr}$. Electrolyte leakage (EL) and leaf water soaking (WS) evaluation were performed using the methods described by Mollá et al. (2006) and Wongsheree et al. (2009), respectively. The concentration of malondialdehyde (MDA) as amount of lipid peroxidation (LP) was identified according to Siboza et al. (2014). In order to determine total soluble carbohydrates (TC), the process described by Dubois et al. (1956) was employed. Antioxidant capacity (AC) was assayed according to Siboza et al. (2014). In addition, proline content (PC) was estimated by the method introduced by Bates et al. (1973). Superoxide dismutase activity (SOD) was determined using the method recommended by Wu et al. (2006). Moreover, ascorbate peroxidase activity (APX) was evaluated based on Rivas et al. (2008) recommended method. Statistical values were estimated for each trait using SAS v. 9.1.3.

\section{Results and Discussion}

The traits evaluated indicated that there was wide range of reaction to CS (Table 2). The results indicated that the highest coefficient of variation $(\mathrm{CV})$ was recorded for $\mathrm{EL}$ at $-3^{\circ} \mathrm{C}(40 \%)$.

The variance analysis results obtained by using the split-plot design for the eight examined traits are presented in Table 3. Differences between genotypes were significant in all the studied traits and indicated that there was a high genetic diversity within the studied accessions, which largely confirmed the primary assumptions of the present study. The interaction effect of temperature $\times$ genotype, which was statistically significant at 0.01 level for all the evaluated traits except APX, indicated a high diversity among genotypes in terms of response to CS. Based on the statistical aspects and significant interactions, it was necessary to perform the cutting operation. Therefore, the statistical analyses were done at each temperature separately.

To evaluate the effect of CS on the measured traits, the average variation of genotypes was calculated for each trait (Fig. 1). According to the results, with an increase in stress intensity, only the traits change of cell degradation index had an enhancing trend. The similarity of change trend in these three traits confirmed that with an increase in CS and ROS the production cell membrane destruction enhanced as well. In the present study, the maximum accumulation of malondialdehyde as a result of oxidative stress on lipids peroxidation was recorded at $-6^{\circ} \mathrm{C}$. The maximum increase of $\mathrm{AC}$ at $-3^{\circ} \mathrm{C}$ by the revival of the free radicals can be effective in inducing cold acclimation and tolerance in stressed plants. After that, with an increase in stress intensity at $-6^{\circ} \mathrm{C}$, a decrease in AC was observed. For TC and SOD activity, the highest value was observed at $0^{\circ} \mathrm{C}$ (Fig. 1). For EL, Poncirus (G103), Satsuma mandarin (G96) genotypes and the unknown biotypes G8 showed the least change in comparison (Fig. 2) with the initial stress temperature (8.53, 9.24 and $9.83 \%$, respectively). In contrast, the Mexican lime genotype (G109) and the two unknown biotypes G48 and G16 had the highest change rate relative to $-3^{\circ} \mathrm{C}(42.44,40.36$ and $39.29 \%$, respectively). In fact, high EL levels indicated the inability of the membrane to retain intracellular compounds, as well as loss of selective permeability, greater excretion of electrolytes from the cell, and damage to cell membrane. However, the lowest PC concentration was recorded for G67, G49 and G22 biotypes ( 8.53, 9.69 and $9.89 \mathrm{mg} / \mathrm{g}$ leaf fresh weight, respectively) (Fig. 3). For AC, the highest amount of variation was recorded for Poncirus (G103) (39.23\%). After that, Satsuma mandarin (G96) with $38.23 \%$ and Off type sour orange (G110) with $36.52 \%$ had the highest AC changes compared to the initial stress temperature. Pearson correlation coefficient was used to show the relationships between the traits, which are presented in Table 4. Since CT is a 


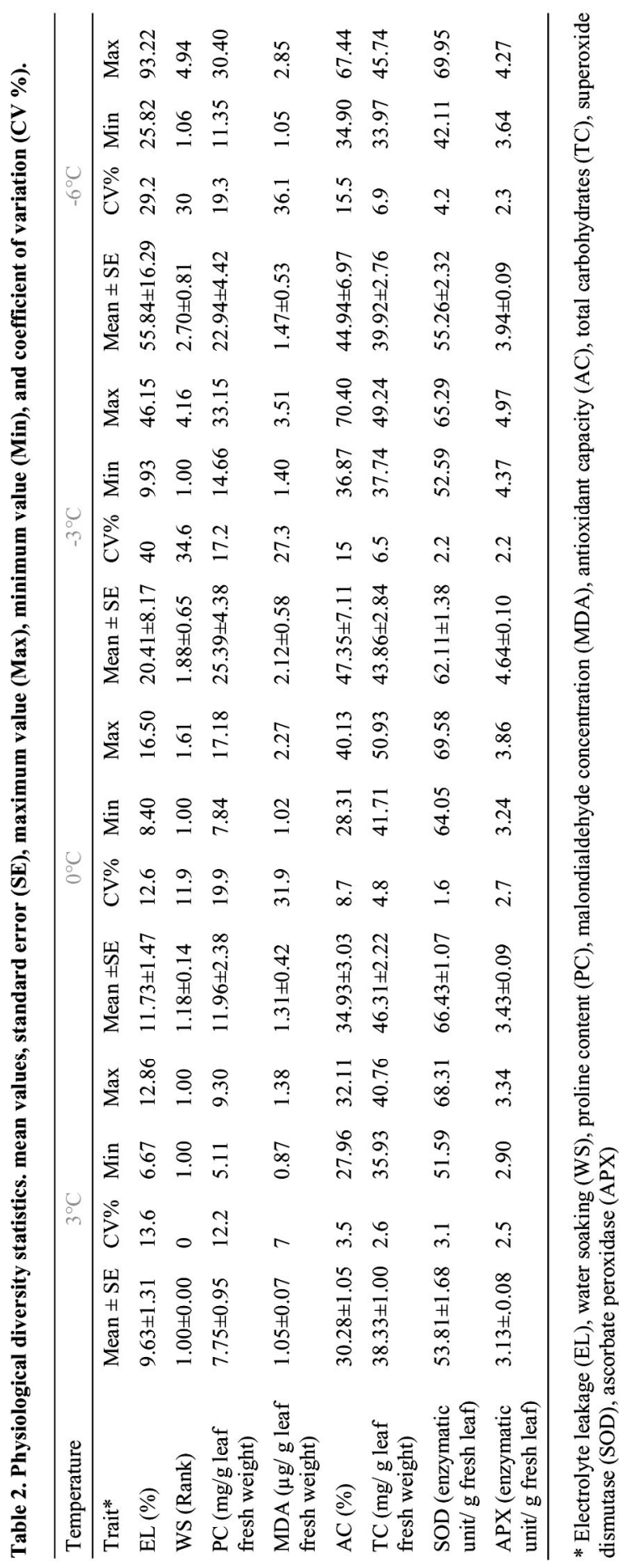




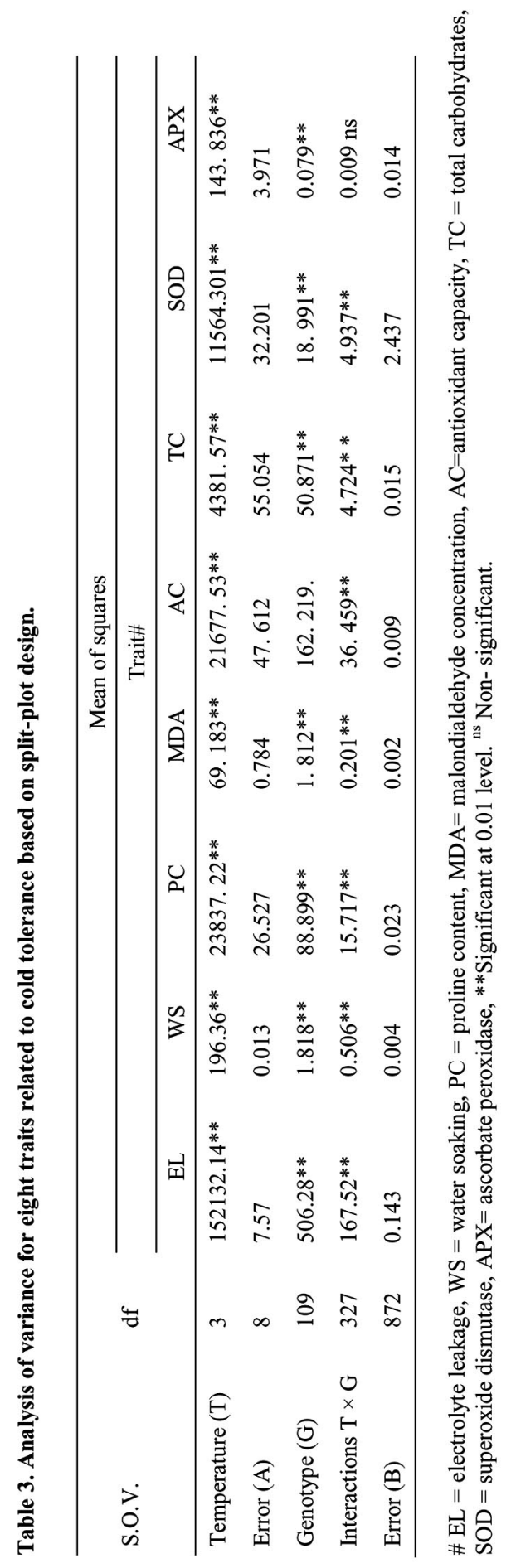



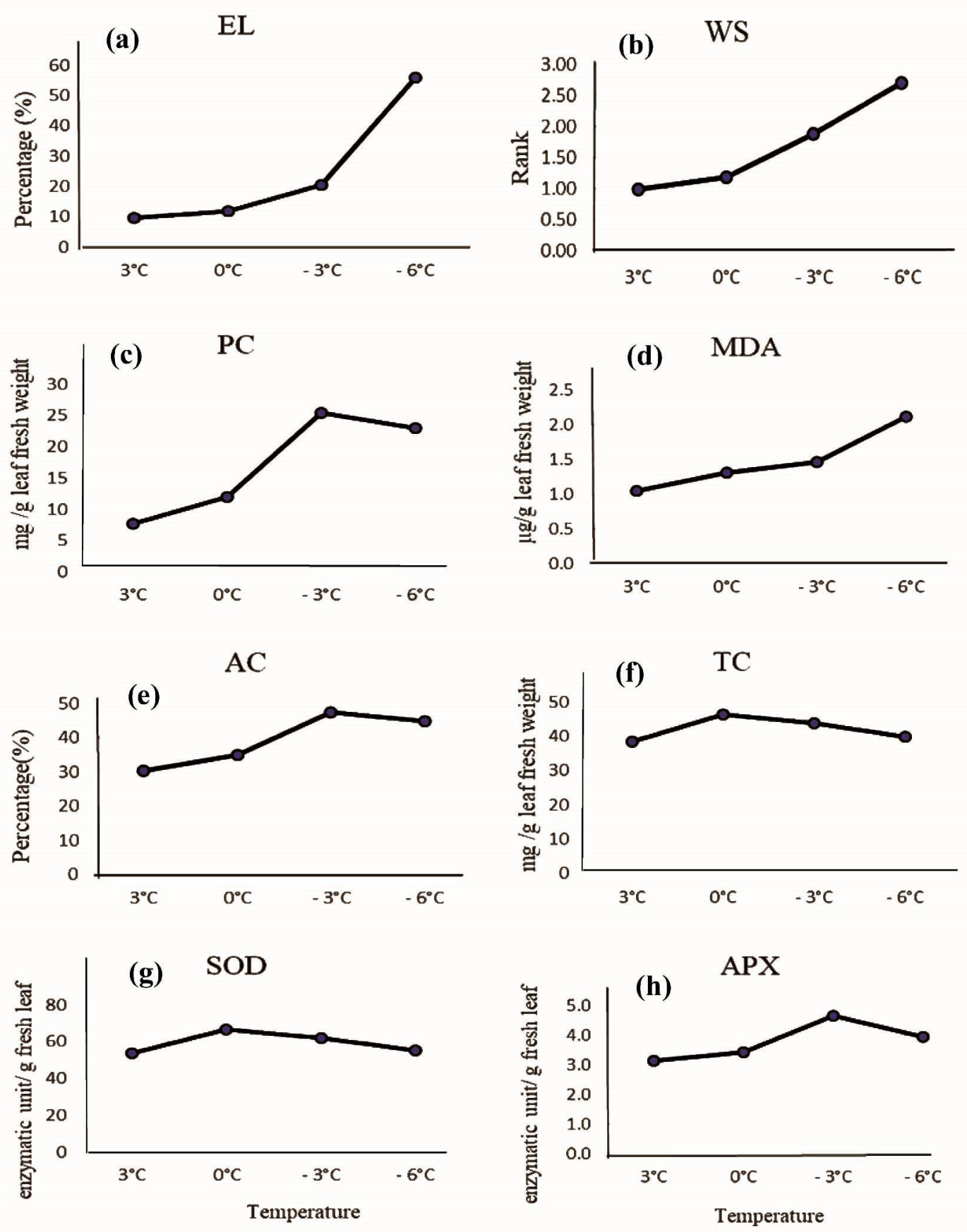

Fig. 1. The trend of mean variation of studied traits at four stress temperatures. (a) EL= electrolyte leakage, (b) WS = water soaking, (c) $\mathrm{PC}=$ proline content, (d) MAD = malondialdehyde concentration, (e) $\mathrm{AC}=$ antioxidant capacity, (f) TC = total carbohydrates, (g) SOD = superoxide dismutase activity, (h) APX = ascorbate peroxidase activity. 

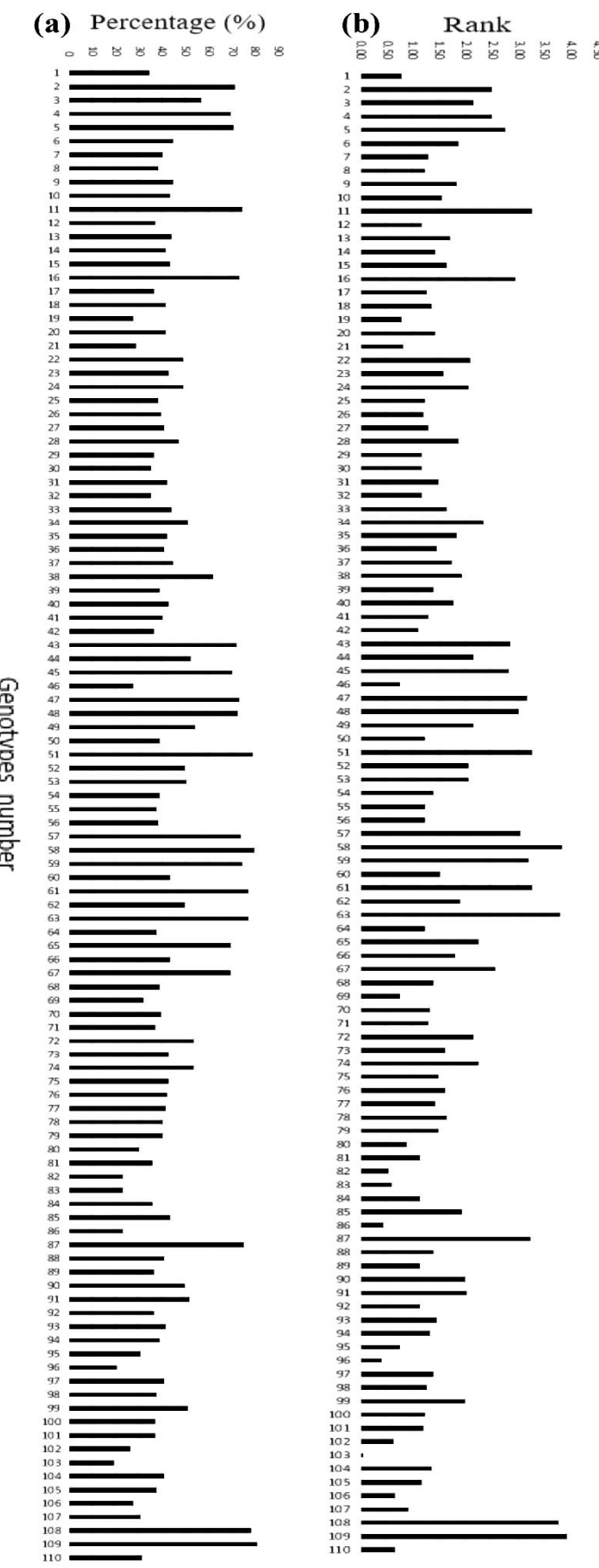

(c) $\mu \mathrm{g} / \mathrm{g}$ leaf fresh
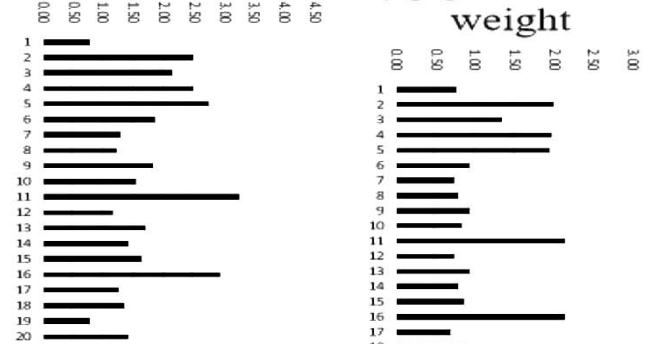

永2
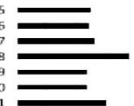

$\equiv$

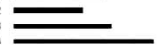

$\overline{=}$

$\overline{\bar{\equiv}}$

$\overline{\overline{\bar{z}}}$

$\overline{\bar{\equiv}}$

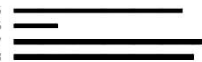

$\overline{\overline{2}}$

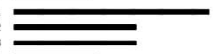

$\bar{\equiv}$

$\overline{\bar{z}}$
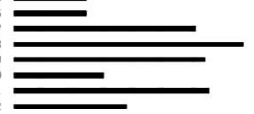

$\overline{\overline{2}}$

$\overline{\underline{Z}}$

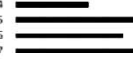

$\bar{\equiv}$

$\overline{\bar{E}}$

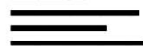

$\overline{\bar{\equiv}}$

$\overline{\bar{\equiv}}$

$\bar{\equiv}$

$\bar{\equiv}$

${ }_{85}^{83}=$

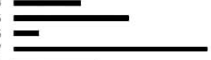

$\bar{\equiv}$

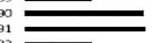

作

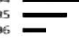

$\overline{\overline{1}}$

100
101
102

102
103
105
105

${ }_{105}^{105}$
105
108
109

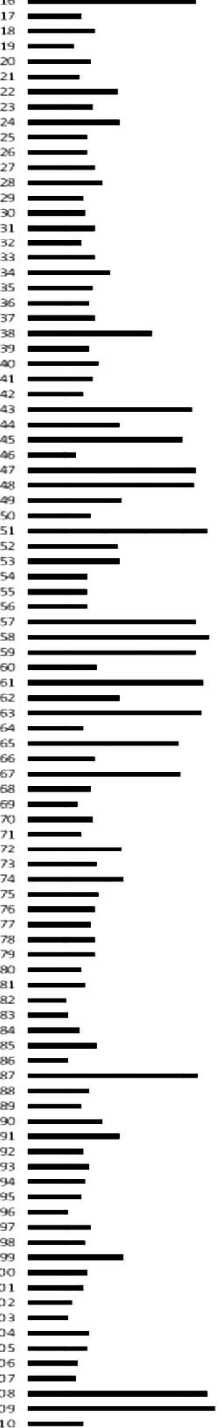

Fig. 2. The variation amplitude values of 110 citrus genotypes relative to the initial temperature of stress $\left(3^{\circ} \mathrm{C}\right)$ for the three traits of cell degradation index. (a) Electrolyte leakage, (b) Leaf water soaking, and (c) Malondialdehyde concentration. 
(e)

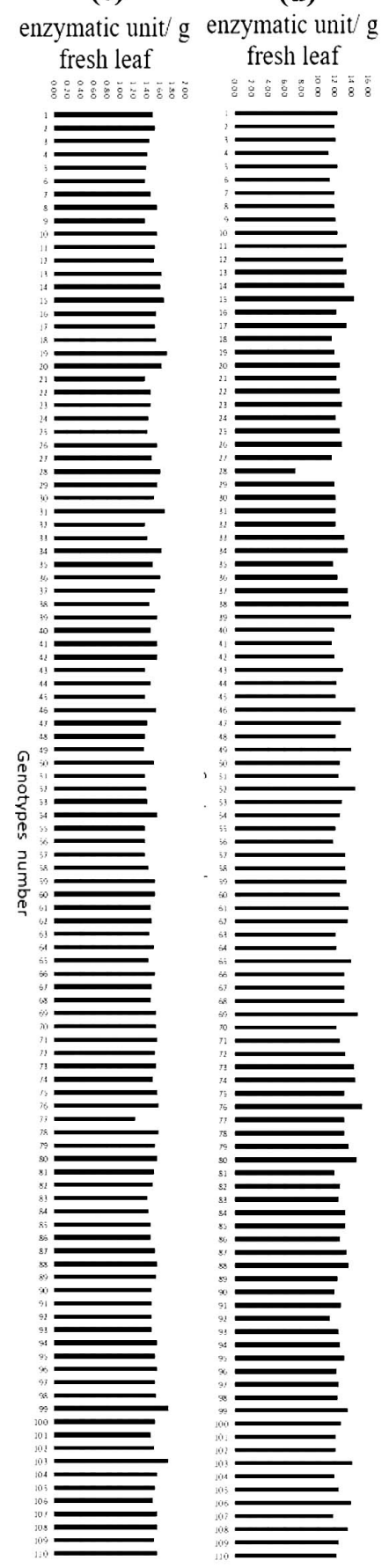

(c) $\mathrm{mg} / \mathrm{g}$ leaf fresh

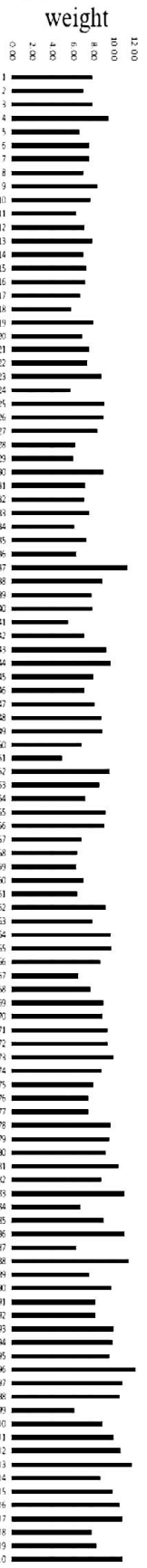

(b)

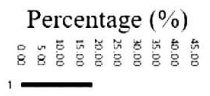

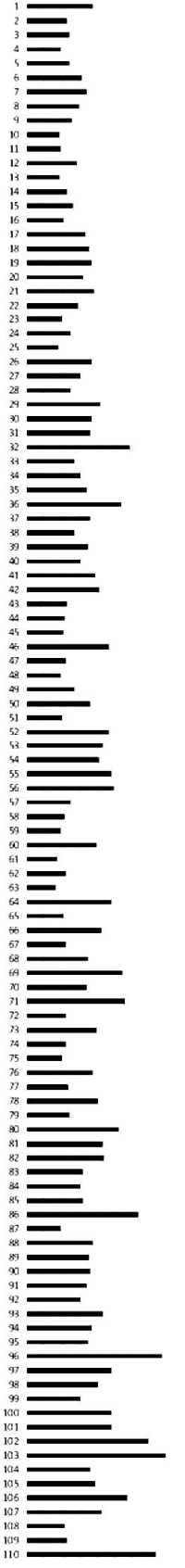

(a)

$\mathrm{mg} / \mathrm{g}$ leaf fresh weight

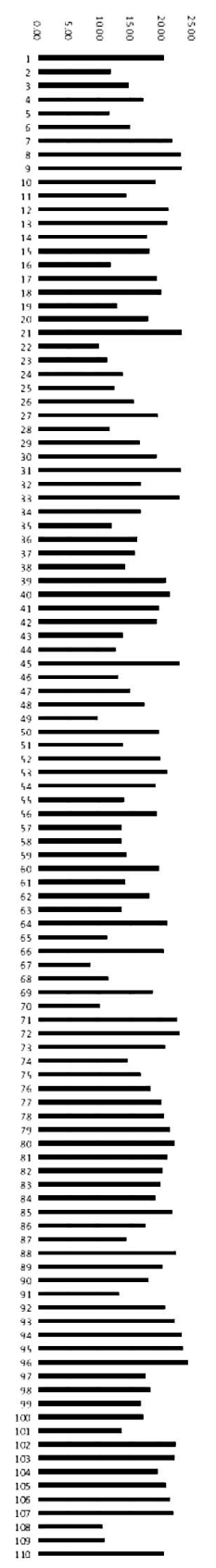

Fig. 3. The variation amplitude values of 110 citrus genotypes relative to the initial temperature $\left(3^{\circ} \mathrm{C}\right)$ for the traits associated with induction of cold tolerance. (a) Proline content, (b) Antioxidant capacity, (c) Total soluble carbohydrates, (d) Superoxide dismutase activity, and (e) Ascorbate peroxidase activity. 
quantitative trait, it was expected to record different correlation values between the traits. In the present study, the highest positive significant correlation (very strong)was observed between EL and WS at the level of $0.01(\mathrm{r}=0.91)$.

All the traits that were involved in CT induction had a sigmoidal response to different CS levels. This kind of sigmoid trend caused by an increase in CS intensity was reported earlier in other studies (Tajvar et al. 2011) and is justifiable. It can be said that an increase in ROS, in competition with oxidative inhibitors of these free radicals, leads to the degradation of macromolecules such as proteins and nucleic acid. As a result, the biosynthetic pathway of many active enzymatic and non-enzymatic metabolites was affected in resistance induction to stress, and an irreversible damage was imposed on the cell. Consequently, on the nature of the plant's genotype (susceptible or tolerant), the continuity of this stress will be accompanied by further degradation of cellular organelles and inactivation of CT molecular mechanisms.

Table 4. Correlations coefficients between eight traits related to cold tolerance used in present study.

\begin{tabular}{|c|c|c|c|c|c|c|c|c|}
\hline Trait & EL & WS & $\mathrm{PC}$ & MDA & $\mathrm{AC}$ & TC & SOD & APX \\
\hline Electrolyte leakage (EL) & 1 & & & & & & & \\
\hline Water soaking (WS) & $0.91 * *$ & 1 & & & & & & \\
\hline Proline content (PC) & $0.42 * *$ & $0.45^{* *}$ & 1 & & & & & \\
\hline Malondialdehyde conc. (MDA) & $0.35 * *$ & $0.59 * *$ & $0.34 * *$ & 1 & & & & \\
\hline Antioxidant capacity (AC) & $0.29 * *$ & -0.28 & $0.85 * *$ & $0.18 * *$ & 1 & & & \\
\hline Total Carbohydrates (TC) & $-0.35 *$ & -0.30 & $0.24 * *$ & -0.04 & $0.32 * *$ & 1 & & \\
\hline Superoxide dismutase (SOD) & $0.33 *$ & -0.20 & $0.08 * *$ & $0.20 *$ & $0.12 *$ & $0.74 * *$ & 1 & \\
\hline Ascorbate peroxidase (APX) & $0.29 *$ & $-0.44 * *$ & $0.84 * *$ & $0.56 *$ & $0.74 * *$ & $0.26 * *$ & $0.18 * *$ & 1 \\
\hline
\end{tabular}

**Significant at 0.01 level, *Significant at 0.05 level.

In the present investigation, an increase in PC confirmed the previous studies that PC can be used as one of the tolerant indices in the selection of tolerate genotypes (Rai and Penna 2013). As one of the most compatible compositions, it can actually play an antioxidant role through reviving free radicals, in addition to decreasing osmotic potential (Ashraf et al. 2007). Regarding the maximum amount of $\mathrm{EL}$ and $\mathrm{WS}$ at $-6^{\circ} \mathrm{C}$ due to the decomposition of unsaturated fatty acids, similar results were observed for LP. However, the remaining metabolites from different defense mechanisms in more tolerant genotypes, including antioxidant defense systems (despite the decrease in activity at $-6^{\circ} \mathrm{C}$ ), caused a moderate delay in cell membrane degradation. In some plants, at temperatures above $0^{\circ} \mathrm{C}$, EL levels are not affected. One of the strategies that many plants take to survive under low-temperature stress conditions is using antioxidant compounds (enzymatic or non-enzymatic) (Wu et al. 2010). Having considered a decrease in AC and an increase in stress intensity from $-3^{\circ} \mathrm{C}$ to $-6^{\circ} \mathrm{C}$, it can be deduced that by increasing ROS density, these radicals appeared beyond the role of a signal, act as a destructive factor and reduce the efficiency of plant defense mechanisms. This sigmoidal trend is similar to the results reported by Tajvar et al. (2011). Due to the contribution of tolerant genotypes rather than sensitive genotypes to the population tested, different results from the average of different traits values at various stress temperatures were expected. During temperature decrease, APX enzyme activity increased to prevent damage to the plant and maintain homeostasis. Due to the lack of increase in APX enzyme activity at temperatures below $-3^{\circ} \mathrm{C}$ and the main role of this enzyme in controlling hydrogen peroxide, it can be said that the hydrogen peroxide decomposition peak was at $-3^{\circ} \mathrm{C}$. The sharp decrease in metabolic activity at temperatures below $-3^{\circ} \mathrm{C}$ caused less hydrogen peroxide formation. As a result, there was no need to increase APX enzyme (Yong et al. 2008). Moreover, in many genotypes, it is not possible to continue enzymatic activity for their accumulation. Of course, it should be noted that due to the presence of soluble materials in the 
cell, the freezing point or physiological zero of the plant (depending on the genotype) may reduce to $-3^{\circ} \mathrm{C}$, and naturally, physiological processes may continue to reach this temperature (Tarkowski and Van den Ende 2015). In contrast, membrane degradation, as well as EL and WS, are physical processes and parallel to a further fall in temperature, the amount of freezing and membrane destruction would increase.

The intensity of change in response to stress in various genotypes was different (Figs 2 and 3). It is possible to justify the big difference of TC concentration between tolerant and sensitive accessions by saying that in tolerant genotypes, an increase in the density of sugars under lowtemperature stress conditions was because of the enhancing process of converting starch into soluble sugars or reducing their consumption due to the reduction in metabolic processes (Tarkowski and Van den Ende 2015). Conversely, in sensitive accessions, a reduction in TC under stressful temperature can be due to the use of sugars in the synthesis of some metabolites such as proline in the leaves. It may be concluded that changes in carbohydrates concentration are very important in inducing tolerance mechanisms because these compounds directly affect important physiological reactions such as photosynthesis and respiration. The results showed that, relative to the initial stress temperature, the studied genotypes had a relatively low diversity in terms of the range of SOD enzyme changes (Fig. 3). Accordingly, citron genotype (G76) and G69 biotype, with the estimated 15.20 and 14.77 units of enzyme per gram of leaf fresh weight respectively, had the highest range of enzymatic activity change. The lowest enzyme changes were recorded for G28 and G4 genotypes. In justifying the positive significant correlation between EL,WS and LP, it could be noted that free radicals in the cell caused damage to the lipids and fatty acids of cell membrane and, by expediting the LP process and malondialdehyde formation, created a physiological degradation of cell membrane. Therefore, further degradation of membrane lead to an increase in the leakage of cellular contents into an intercellular space. On the other hand, physical damage such as freezing and ice core formation could also affect leakage rate and WS, and the calculated correlation confirmed this interpretation.

Moreover, based on the positive significant correlation between APX and LP, it may be concluded that the production of more hydrogen peroxide resulting from stress produces more malondialdehyde and, consequently, decreased membrane stability, which resulted in increased APX activity for decomposing hydrogen peroxide. Wang et al. (2009), in their study on the effect of abiotic stress on antioxidant enzymes activity, reported that CT genotypes had less hydrogen peroxide accumulation. In this regard, similar results were obtained from the process of increasing APX enzyme and reducing hydrogen peroxide in other plants (Guo et al. 2006). It was found that the traits associated with CT had a compensatory effect on each other and, by decreasing the efficiency of a system, other defense mechanisms acted considerably to reduce the amount of cell damage. However, with an increase in cellular degradation, the plant cannot inhibit free radicals and eliminate them, and as a result, the effectiveness of CT induction mechanisms is reduced (Gill and Tuteja 2010). It was observed that among the genotypes, Poncirus, Satsuma mandarin, and various sour orange genotypes showed the highest CT, so the efficiency of these genotypes in breeding programs was confirmed. It was also determined that some unknown biotypes for one or more of the studied traits had a high breeding and selection value. On the other hand, the evaluations showed that the optimal values of all the resistance criteria were not the highest in known tolerant genotypes. For example, for SOD enzyme, citron genotype (G76) and the unknown biotype G69 showed the highest change in enzymatic activity. The most important indicator in the survival assessment of Citrus genotype in CS condition was EL, which, if increased by more than $50 \%$, would indicate the death of the organ or tissue. It may be concluded that due to genetic structure and physiological factors, there was a significant difference between the reaction of different accessions against CS. Hence, some genotypes were prominent for at least 
one associated trait with CT. Increasing the range of temperature changes, employing a variety of traits, evaluating growth stages, using different varieties and genotypes, and finally, exploiting molecular markers can lead to a better recognition of tolerant genotypes and their uses in breeding programs.

\section{References}

Ashraf M and Foolad MR 2007. Roles of glycine betaine and proline in improving plant abiotic stress resistance. Environ. Expt. Bot. 59: 206-16.

Bates L, Waldren R and Teare I 1973. Rapid determination of free proline for water-stress studies. Plant Soil 39: 205-207.

Dubois M, Gilles KA, Hamilton JK, Rebers PT and Smith F 1956. Colorimetric method for determination of sugars and related substances. Anal. Chem. 28: 350-356.

Gill SS and Tuteja N 2010. Reactive oxygen species and antioxidant machinary in abiotic stress tolerant in crop plants. Plant Physiol. Biochem. 48: 909-930.

Guo Z, Ou W-z, Lu S-y and Zhong Q 2006. Differential responses of antioxidative system to chilling and drought in four rice cultivars differing in sensitivity. Plant Physiol. Biochem. 44: 828-836.

Lindhout K 2007. Physiology of chilling-related postharvest rind breakdown of navel oranges (Citrus Sinensis (L.) Osbeck). Thesis (Ph.D.) - La Trobe University.

Mollá S, Villar-Salvador P, García-Fayos P and Rubira JLP 2006. Physiological and transplanting performance of Quercus ilex L.(holm oak) seedlings grown in nurseries with different winter conditions. For. Ecol. Manage 237: 218-226.

Nesbitt ML, Ebel RC, Findley D, Wilkins B, Woods F and Himelrick D 2002. Assays to assess freeze injury of Satsuma mandarin. HortScience 37: 871-877.

Rai AN and Penna S 2013. Molecular evolution of plant P5CS gene involved in proline biosynthesis. Mol. Biol. Rep. 40: 6429-6435.

Rivas F, Fornes F and Agustí M 2008. Girdling induces oxidative damage and triggers enzymatic and nonenzymatic antioxidative defences in Citrus leaves. Environ. Expt. Bot. 64: 256-263.

Sala JM and Lafuente MT 1999. Catalase in the heat-induced chilling tolerance of cold-stored hybrid Fortune mandarin fruits. J. Agric. Food Chem. 47: 2410-2414.

Siboza XI, Bertling I and Odindo AO 2014. Salicylic acid and methyl jasmonate improve chilling tolerance in cold-stored lemon fruit (Citrus limon). J. Plant Physiol. 171: 1722-1731.

Tajvar Y, Ghazvini RF, Hamidoghli Y and Sajedi RH 2011. Antioxidant changes of Thomson navel orange (Citrus sinensis) on three rootstocks under low temperature stress. Hortic. Environ. Biotechnol. 52: 576-580.

Tarkowski ŁP and Van den Ende W 2015. Cold tolerance triggered by soluble sugars: a multifaceted countermeasure. Front. Plant Sci 6: 203.

Wang W-B, Kim Y-H, Lee H-S, Kim K-Y, Deng X-P and Kwak S-S 2009. Analysis of antioxidant enzyme activity during germination of alfalfa under salt and drought stresses. Plant Physiol. Biochem. 47: 570-577.

Wongsheree T, Ketsa S and van Doorn WG 2009. The relationship between chilling injury and membrane damage in lemon basil (Ocimum $\times$ citriodourum) leaves. Postharvest Biol. Technol. 51: 91-96.

Wu QS, Zou YN and Xia RX 2006. Effects of water stress and arbuscular mycorrhizal fungi on reactive oxygen metabolism and antioxidant production by citrus (Citrus tangerine) roots. Eur. J. Soil Biol. 42: $166-172$.

Wu QS, Zou YN, Liu W, Ye XF, Zai HF and Zhao LJ 2010. Alleviation of salt stress in citrus seedlings inoculated with mycorrhiza: changes in leaf antioxidant defense systems. Plant Soil Environ. 56: $470-475$.

Yong Z, Hao-Ru T and Ya L 2008. Variation in antioxidant enzyme activities of two strawberry cultivars with short-term low temperature stress. World J. Agric. Sci. 4: 458-462.

(Manuscript received on 22 April, 2019; revised on 18 August, 2019) 